${ }^{2}$ Drake DP. Acute abdominal pain in children. $J R$ Soc Med 1980;73:641-5.

D P DRAKE

Guy's Hospital,

London SE1 9RT

\section{Insufficient early weight gain in preterm babies and influence on weight at 12 months}

Sir,

In an interesting though difficult paper Davies and Kennedy ${ }^{1}$ report that there was no influence of insufficient early weight gain in preterm babies on weight at 12 months.

I would like to comment on their introductory remarks that anxieties about poor early weight gain were 'based largely and often uncritically on studies in laboratory animals', citing a (wrongly dated) 19 year old paper by Winick and Noble that has now lost its currency, ${ }^{2}$ a classic paper of Widdowson and McCance, and an old one of our own.

It is true that paediatricians' extrapolations from other animals to man are often uncritical, to the point that they may be rejected altogether except where they seem to bolster emotional belief, ${ }^{3}$ and this example is no exception. At the same time such comparisons can be very useful and should not be dismissed until they have been properly made. At the very least they must take account of the different time scales of growth between species, the different timing of birth in relation to developmental stages, and, especially, comparable stages of growth must be compared before the self evident conclusion is pronounced that animals are 'of course' not always like man.

In the present case growth restriction between birth and three weeks of age in the rat clearly results in a permanent resetting of the growth trajectory downwards, with ultimate stunting in adulthood, and in certain permanent alterations of brain anatomy and function. The comparable period in man is much longer, from about the beginning of the first trimester of gestation until about the second birthday. Whether or not man has a similar vulnerable period to that in rats awaits a demonstration of the long term consequences of growth restriction lasting for a major part at least of this very long period in humans, such restriction being to a comparable degree, so that by the age of 2 the child is not much more than half its ordained size, the outcome being assessed not earlier than the late teens. Of course, it is much easier to produce these conditions in experimental animals, but that is the whole point of using them. Children do exist, especially in underprivileged communities, whose early growth experience comes reasonably close to the model suggested by Widdowson and McCance in the rat, and there is reason to believe that in them a critical extrapolation bears fruit, the people in such communities being generally stunted. That the reason for their smallness is by no means wholly genetic is evident from their children's response to the arrival of better environmental conditions, when they are seen to outstrip the growth attainments of their parents, often dramatically.

I hope that the strictures of Davies and Kennedy about extrapolating from animals to man will be heeded, not least by themselves!

\section{References \\ ${ }^{1}$ Davies DP, Kennedy JD. Insufficient early weight gain in preterm babies and influence on weight at 12 months. Arch Dis Child 1985;60:718-21. \\ 2 Sands J, Dobbing J, Gratrix CA. Cell number and cell size: organ growth and development and the control of catch-up growth in rats. Lancet 1985 ;ii:503-5. \\ 3 Dobbing J. Breast is best isn't it. In: Freed DLJ, ed. Hazards of milk. London: Bailliere Tindall, 1984:60-74.}

JoHN DoBBING University of Manchester, Manchester M13 9PT

Professor Davies and Dr Kennedy comment:

We are grateful to Professor Dobbing for his comments. These serve to strengthen even further our already held conviction of the need to consider and analyse very carefully any extrapolations that might be made from animals to man in regard to effects of nutrition on early growth. We will be dutiful in applying these strictures to ourselves!

\section{Impact of neonatal care-South West Thames region (less than 1000 grams)}

Sir,

Thompson and Khot $^{1}$ have reported on the Brighton (South East Thames) experience on the reduction of mortality with the introduction of respiratory support. Not only does local mortality improve but so do expectations, and this is not just confined to the centres providing full neonatal intensive care with respiratory support. In the next door South West Thames region intensive care began probably with the opening of a new unit at St George's in 1980. In the five years $1980-84$ inclusive there has been a steady improvement in mortality figures both at St George's and generally in the region. This has been accompanied by a regional increase in expectations. This is illustrated by the Table.

In 1980, 53 infants delivered with a birthweight less than $1000 \mathrm{~g}$ were resuscitated in the region, $13(24 \%)$ at St George's Hospital. Since then there has been a steady increase, so that in 1984 there were 72 infants of this weight resuscitated, $28(39 \%)$ at St George's. In 1980 only eight infants $<1000 \mathrm{~g}$ in the region survived to go home, four $(50 \%)$ from St George's-that is, only $15 \%$ of those resuscitated. This had increased to 39 infants in 1984, of whom $18(46 \%)$ were delivered at St George's. Thus the overall regional survival for babies of this weight group has increased to $54 \%$. Not only are more infants of this extremely low birthweight being resuscitated, but they are 
Table South West Thames: No (\%) of babies of birthweight $<1000 \mathrm{~g}$ resuscitated and surviving to go home

\begin{tabular}{|c|c|c|c|c|c|}
\hline & 1980 & 1981 & 1982 & 1983 & 1984 \\
\hline $\begin{array}{l}\text { Resuscitated: } \\
\text { St George's Hospital } \\
\text { Rest of SW } \\
\text { Thames region }\end{array}$ & 13 & 18 & 18 & 27 & $\begin{array}{l}28 \\
44\end{array}$ \\
\hline Total & 53 & 57 & 60) & 64 & 72 \\
\hline $\begin{array}{l}\text { Surviving to } \\
\text { go home: } \\
\text { St George's Hospital } \\
\text { Rest of SW } \\
\text { Thames Region }\end{array}$ & $\begin{array}{l}4(31) \\
4(10)\end{array}$ & $\begin{array}{l}10(56) \\
10(26)\end{array}$ & $\begin{array}{c}9(50) \\
17(40)\end{array}$ & $\begin{array}{l}16(59) \\
11(30)\end{array}$ & $\begin{array}{l}18(64) \\
21 \quad(48)\end{array}$ \\
\hline Total & $8(15)$ & $20(35)$ & $26(43)$ & $27(42)$ & $39(54)$ \\
\hline
\end{tabular}

being effectively resuscitated and generally around the region are being managed so that they can go home. The greater expectations have implications for the provision of care. Intelligent anticipation by regional obstetricians with in utero referral is now commonplace, and baby units that are not staffed to practise even short term care provide effective resuscitation, so that the percentage of infants dying before transfer to an intensive care unit has fallen from $40 \%$ in 1980 to $19 \%$ in 1984 .

\section{References \\ 1 Thompson MH, Khot AS. Impact of neonatal intensive care. Arch Dis Child 1985;60:213-4.}

NeIL McINTOSH St George's Hospital Medical School, London SWI7 ORE

\section{Food related asthma: a difference between two ethnic groups}

\section{Sir,}

I read the article by $\mathrm{N} M$ Wilson ${ }^{1}$ with interest. I was not surprised by the findings and feel I must express some reservation regarding its conclusions.

As a severely atopic child growing up in South India I can remember well my parents' admonitions relating to iced and fizzy drinks, fried foods, nuts, and chocolate. A deep sense of guilt, and a heavy wheeze, often accompanied my return home from children's parties. In the family inquest that usually ensued the atmosphere of dark suspicion and recrimination did little to alleviate bronchospasm. A school mate suffering from recurrent cystitis had similar food restrictions imposed (ice 'brought a chill to the kidneys').

Auto suggestion certainly played a major role in my reaction to foods. When, at the age of 21 , I made the decision to remove milk and eggs from my diet a complete and permanent resolution of eczema resulted within weeks. Asthma that had been controlled for eight years only by the use of continuous systemic steroids regressed to four or five attacks a year. These are now triggered off by common antigen exposure-that is, house dust, pollens, and heavy exercise.

There are widespread food taboos on the subcontinent. The above mentioned foods are often incriminated in many relapsing ailments-for example, diarrhoea and migraine. Conversely, foods considered beneficial, like milk and eggs, are rarely, if ever, considered for indictment.

I therefore find it difficult to accept the conclusion that Asian asthmatic children have food sensitivities that are in any way excessive or peculiar. A control study of Asian children with non-asthmatic chronic disorders might be of value. It would also be interesting to know what proportion of the children studied derived from homes where first or second generation traditional influences still apply.

Camille de San lazaro Royal Victoria Infirmary, Newcastle upon Tyne NEI 4LP

\section{Dr Wilson comments:}

The implication of Dr de San Lazaro's letter is that the ethnic difference found in the survey could merely be the spurious result of cultural taboo and that any experience of food related asthma in the Asian children was due to suggestion. She provides no evidence, however, that her symptoms as a child, after ingestion of certain incriminated foods, were in fact psychogenically determined rather than a genuine response to the ingested substances. In contrast, the claim that ice, fizzy drinks, and fried foods can precipitate asthma in Asian subjects was based on the results of controlled challenge tests. ${ }^{1-3}$ I think it highly unlikely that these positive responses were due to suggestion even when the tests were performed single blind. For example, ice but not placebo induced a significant increase in bronchial responsiveness that was greater at 90 than 30 minutes after ingestion, without a change in resting lung function. 'Because of the way the tests were conducted the subjects were unaware whether a positive response had occurred or not. Suggestion can undoubtedly induce bronchoconstriction, but an increase in bronchial responsiveness due to psychogenic factors has not been reported. Admittedly, one cannot be sure that every child giving a positive answer in the survey had experienced such an effect nor that all those with negative answers had not. However, positive histories were confirmed in almost all of the Asian children challenged with ice, ${ }^{2}$ cola drinks, ${ }^{3}$ and fried foods. ${ }^{1}$ On the other hand, asthma in the older child due to milk or egg intolerance, in the experience of myself and others using diagnostic elimination diets, is uncommon. It is not suggested that the incriminated substances are the cause of asthma in Asian children but rather that they act as an asthmogenic stimulus, as do exercise and smoke in asthmatics in general.

A control study of Asian children with non-asthmatic chronic disorders might be interesting but irrelevant. The fact that other disorders such as cystitis may be erroneously 